SOCIAL RESEARCH REPORTS

ISSN: 2066-6861 (print), ISSN: 2067-5941 (electronic)

\title{
RESPONSIBLE ALCOHOL CONSUMPTION AND EUROPEAN
} PUBLIC POLICY

\section{Calina-Ana BUTIU}

Social Research Reports, 2019, Vol. 11, Issue 3, pp. 153-165

The online version of this article can be found at:

www. researchreports.ro

https://doi.org/10.33788/srr11.3.11

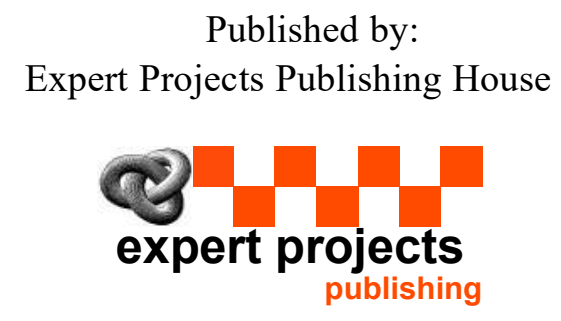

Covered by Index Copernicus International www.indexcopernicus.com

Directory of Open Access Journals www.doaj.org

On behalf of:

Center for Program and Social Development

Aditional services and information about Social Research Reports can be found at: www.researchreports.ro 


\title{
RESPONSIBLE ALCOHOL CONSUMPTION AND EUROPEAN PUBLIC POLICY
}

\author{
Calina-Ana BUTIU ${ }^{1}$
}

\begin{abstract}
The detrimental effects of alcohol consumption have been the subject of numerous research works from various fields, particularly due to its social impact. As part of public policy, alcohol consumption has frequently been included in national and supranational agendas and eliciting many research studies, reports and consumption reduction strategies. World Health Organization statistics-based reports name European countries as having among the highest levels of alcohol consumption and, while the reduction of it is a stated European Union policymaking objective, the conclusions of the studies are not easily discernible, and the practical results achieved so far, not that effective. In a world of abundance, excessive alcohol consumption remains a rather elusive problem of public policy, due to the complexity of its interactions with all of the biological, psychological and social environments. Many studies so far suggest that the right policy may not be complete abstinence, but rather an approach based on a responsible level of consumption.
\end{abstract}

Keywords: alcohol consumption, public policy, European Union, cost-benefit analysis.

\section{Introduction}

Alcohol consumption has been the subject of a vast literature due to its effects in many public domains like medical, social or economic. Drinking in social contexts has been a traditional human activity for ages, alcohol appearing to have certain social bonding functions. As Skog puts it "To drink is to be together" (Skog, 2006). While the cost-benefit analysis of alcohol intake is rather difficult to make, due to the elusiveness of capturing the (mostly subjective) benefits, there is a quasi-universal agreement among researcher that the costs of even moderate drinking outweigh the benefits. Young people - being the category that is most

\footnotetext{
${ }^{1}$ Universitatea "1 Decembrie 1918" din Alba Iulia, Alba Iulia, ROMANIA. E-mail: bcalina@yahoo.co.uk,
} 
impressionable and most inclined towards social connections - are most vulnerable, so the pro-active prevention policies have been targeted primarily towards them.

It is not the objective of this study to draw the line, beyond which alcohol consumption becomes excessive or detrimental, nor to stigmatise alcohol producers or drinking in general, but to review some of the background literature and past attempts at policies intended to tackle the problem of alcohol. Under that understanding, further references to the "problem of alcohol" or to "the consumption of alcohol" or to "alcohol" in general should be interpreted as "the detrimental effects associated with excessive consumption of alcohol".

Alcohol consumption is not just a health problem, but also a socio-economic problem having impact on the inequality of income. In a recent study, Forster, Kentokelenis and Bambra, (2018), claim that the health hazards result in both direct and indirect economic losses. In 2017, in the European Union, this amounted to somewhere between 200 and 500 billion euros. In addition, these estimates usually abstract intangible costs related to pain and diminished quality of life costs which are usually borne by the drinkers and their close environment. To these one can add the medical costs (i.e. hospitalisation) (Jarl, Gerdtham, Lyttkens, Lithman and Merlo, 2006).

The effects of alcohol are not bore just by the drinker, but by related persons also. Chang, Wu, Chen, Chuang, Hsieh, Lin, and Chen (2010) described the adverse effects of husbands' alcohol intake on the physical and psychological health of their spouses, and how it can lead not just to domestic violence, but even to homicide (Parker and Cartmill, 1998). MacDonald and Shields (2001) describe some of the negative occupational effects, although some say they have not been proven beyond reasonable doubt. Although common sense tells us that alcohol consumption should have negative effects on the ability to find jobs, on employee's chances of being hired, on punctuality and on productivity overall, Asgeirsdottir and McGeary (2009) claim that the causality has not been proven in clear terms, and that not all the determining factors may have been considered. It is not clear for instance if unemployment is the effect of alcoholism, its cause, or an intermediate factor that seems to feed the vicious loopback between the two.

There also are indications that alcohol affects civil status. Individuals who are heavy drinkers are more likely to be unmarried than married. Continued heavy drinking over a longer period could have detrimental effects on health, occupation, and social-economic status, which may all, in turn, affect the chance of a marital union formation (Keenan, Kenward, Grundy and Leon, 2014). A good portion of the reduction in life expectancy in the last decades can be attributed to drinking and smoking (Borisch, 2014). Alcohol consumption tackling policy became thus a notable part of European public health policy. Italy's approach during times of crisis is an example (McDaid et al., 2013). Road safety is also gaining more attention in developed countries, due to the increase in the number of deaths resulted from car accidents. Many public policies attack frontally the alcohol consumption behind the wheel (Albalate, 2008).

The predictors of alcohol consumption are arguably diverse. Thorlindsson, Bjarnason and Sigfusdottir claim that individual background, parental relations, adolescent activities, school level of intergenerational closure and cultural activities, are predictive of less alcohol use (2007). Within the framework of 
the Durkheimian theory of family and religion background premises of youth alcohol consumption, Bjarnason et al. (2005) interpreted Irish school data as proof of a negative association between alcohol consumption on one hand, and the traditional family structure, parental control and support, religious involvement, the perceptions of divine support, and the social constraints on the other.

The parents' reaction to teenagers' alcohol consumption is often that of a cutback in parental control and support. One explanation to this reaction was provided by Glatz, Stattin and Kerr (2012), who hypothesized that having to choose between pressing the child to alter behaviour or scaling back parental control, in order to reduce the cognitive dissonance and due to scepticism in the success of the former, parents are inclined to choose the latter.

Lately, the debate on alcohol consumption tends to cluster around two points of view. One of them sees it as determined by the individual choice of lifestyle, while the other one as determined by the social conditions, the resulting lifestyle being the effect of the social premises. These different perspectives obviously lead to different solutions in terms of public policy design. Starting from the premise that the social condition changing policies have not been very successful in the past, Freudenberg (2012) proposes targeting the policies towards personal lifestyle choices rather than towards social changes.

\section{World Outlook}

Statistics show a significant increase in global alcohol consumption during the period following World War II. This is considered mainly due to the increase in purchasing power and in commercial exchanges (Grant, 1985). Based on data from a 1970's World Health Organisation study on alcohol commerce and consumption in 164 countries, M. Adrian (1984) shows that, measured as litres of pure alcohol per capita per year, geographically, the largest amounts were consumed in Europe (8.7), followed by Pacific Islands (7.9), North-America (6.3), South-America (4.1), Africa (2.5) and Asia (0.6). Production and trade of alcohol also increased during the same period in all areas with the exception of Asia. When grouped by the level of development, the increases were clearly more evident in the developed countries than in the less-developed ones. In countries with relatively lower consumption level (2 litres or less), the preference was towards hard liquor (Adrian, 1984). The largest increases in the period from 1960 to 1980 were recorded in the consumption of beer (Grant, 1985).

At the end of the 1990's, the European region was registering the highest alcohol consumption in the world. For the 38 countries with data available on alcohol consumption, the average consumption per person in Europe in 1998 was 7.3 litres. The amount of recorded alcohol consumption ranged from as low as 0.9 litres per person in Azerbaijan and Israel, to as high as 13.3 litres per person in Luxembourg (Rehn, Room, and Edwards, 2001, p.5). According to Alcohol Measures for Public Health Research Alliance (AMPHORA), The European Union remained the region of the world where, by far, the most alcohol is produced and consumed, with a slow trend towards homogenization of drinking patterns 
between countries. It is also notable the fact that the alcohol consumption in southern Europe has been declining for some time concurrently with changes in drinking patterns. The consumption of wine has dropped since the 1970's. In Italy, the drinking patterns amongst young people were starting to look like the ones traditionally found in the West, with beer and spirits consumption on the rise (Anderson, Braddick, Reynolds and Gual, 2012).

The general opinion is that at least $25 \%$ of alcohol production and consumption is not officially accounted for, which not only distorts the real picture, but also generates health risks associated with the quality, toxicity and contamination of alcoholic products (WHO, 2014). The most comprehensive sets of data on alcohol consumption so far have been provided by The World Health Organisation (WHO), particularly through its Global Health Observatory. The recent Global status report on alcohol and health 2018 publication (WHO, 2018) is a comprehensive perspective on global, regional and country consumption of alcohol and on patterns of drinking. Aside from health consequences and policy response recommendations, it provides country profiles and an overview of risk factors to sustainable development in accordance with UN goals. The data gathered from a diversity of statistical, bibliographic and scientific sources showed that in 2016 there were three WHO regions in which alcohol was consumed by more than half of the population - the European Region (59.9\%), the Region of the Americas (54.1\%) and the Western Pacific Region (53.8\%). One of the conclusions is that higher rates of drinking were associated with higher income, the access to alcoholic beverages having been greater for those who are accorded higher or more privileged status (WHO, 2018).

\section{Public Policies on Alcohol Consumption}

If one takes into consideration just the situation in countries with functional democracies, alcohol consumption is by no means discouraged by the state, due most likely to fiscal interests, but also for industrial, commercial, agricultural, social and public order reasons (Mäkelä and Viikari. 1977, p.160). The initial attempts at setting national strategies and policies evolved in the past from incrimination through legalisation and finally to medicalisation (Ștefani, 2018). Later on, the idea of de-medicalisation took shape according to Golden (1999). Hemenway (2001) suggested the alcohol consumption issue be one of public health, rather than one based on prohibition of production or of consumption, the objective being that of reducing the impact on well-being. The challenges of alcohol marketing in view of the vulnerabilities of the youths have been explored in numerous studies (Casswell and Maxwell, 2005; Kessler, 2005; Bjarnason, Thorlindsson, Sigfusdottir, and Welch, 2005; Ogenchuk, 2012; Jernigan and Rushman, 2014).

The fact that addictive substances are a matter of public concern is by now a broadly accepted idea and as such, the health policy making community should be more empowered, sophisticated, more strategically oriented, and should build its grass roots support base (Mosher and Yanagisako, 1991, p. 278). Research on addictive behaviour, which greatly expanded in the last decades, has also been 
used as a foundation for public policy making (Babor, Morisano, Noel, Robaina, Ward, and Mitchell, 2017).

For youth drinking prevention concerns Ogenchuk (2012) recommends the development of transparent and relevant meta-policies that account for both concerned parents' and qualified professionals' opinions. At social level, excesses like binge drinking are convenient to the alcohol industry Spach and Pietri claim (2018), and that is why policy makers are in conflict with the business community.

\section{Alcohol Regulation}

Alcohol regulation is a necessity due to powerful forces at play both in the production and in the consumption of it. The business sector has an obvious interest in increasing production and consumption as much as possible in order to maximize its revenue. Consumers, on the other hand, especially the vulnerable ones, tent to abuse addictive substances, feeding thus a vicious circle with detrimental social effects. Governments, although having an interest in taxing this trade, are the main actors that can break this cycle. Under public pressure, they do attempt some intervention in production and consumption some of it direct and some of it indirect, in secondary, but related areas $^{2}$. Scotland for instance was the first country to impose a minimal price for alcoholic beverages in order to reduce their accessibility (Katikireddi, Bond and Hilton, 2014).

Another frequent area of regulation is the minimum drinking age. There are pressures however in lowering it according to Carpenter and Dobkin, (2011). The minimum drinking age varies from one country to the next, from 21 years old in U. S., to 18 or 19 in Canada and to 16 or 18 in different countries of the European Union. One argument against the lowering of it is the alleged increase in associated deaths from car accidents.

Although there is a general trend of increasing regulation of alcohol publicity, ways to avoid it have become more sophisticated. Jernigan remarks a global increase in alcohol marketing (1999). The explosion of new information technologies resulted in new branding techniques and marketing strategies for alcohol sellers. The classical TV, radio and print media - considered being measured marketing environments - have made room for newer, unmeasured ones like the internet and mobile telephony. This requires action at global level to tackle the challenges of protecting vulnerable groups in the borderless environment of the virtual space (Casswell and Maxwell, 2005). Some reports show an alarming increase in digital alcohol marketing, most exposed to it being the young, which are also the most fervent users of new technologies (Jernigan and Rushman, 2014; Casswell and Maxwell, 2005). An experiment proving that alcohol off-line ad restriction government policies are ineffective was undertaken by Goldfarb and Tucker in 2011. They showed that the restriction of off-line advertising has resulted in an increase in on-line advertising and on-line preferences for both producers and consumers alike. As to youth vulnerability Ross, Ostroff and Jernigan (2014)

\footnotetext{
${ }^{2}$ In Romania, during Ceausescu's socialist regime for instance, austerity was not imposed on all products. Although food was very scarce, alcohol and tobacco were rather plenty. The consumption of them grew as a compensation mechanism against the background of a poor diet.
} 
showed that in U.S., notwithstanding all attempts at regulation and self-regulation, many advertisements are still targeting under-the-drinking-age audiences.

\section{Alcohol Taxation}

In advanced, democratic countries, alcohol taxation is meant as a wealth redistribution mechanism (Lierse, 2012). More recent research suggests that additional taxes could be taken into consideration, as long as the supplemental income would be earmarked towards distinct health objectives, and not towards altering the behaviour of the business community (Hellowell, Smith and Wright, 2016). Additional income could also be used to encourage "healthy retailers" through various subsidies. The pro-alcohol taxation lobby, however, meets resistance from the alcohol producers' one. The taxation is effective for young and for heavy drinkers for which the price of alcohol influences the level of consumption (Hemenway, 2001). Tax increases also leads to lower death rates more so among the young than the elder (Cook, Ostermann and Sloan, 2005).

\section{The Financing of Public Goods}

Educational programs can be ascribed to the set of measures outside direct or indirect regulation. Brady (2017) argues that responsible drinking is achievable through education, the premise of alcoholism not being a disease having emerged in the 60's and the 70'. Brady shows historically how under the behavioural model, United States has financed several studies aimed at defining positive and negative alcohol consumption cultural models, which served thereafter to the development of educational programs targeted at Anglo-Saxon protestant community. The programs however did not return the expected results in the cases of chronic alcoholism, so the disease perspective over alcoholism has been reconsidered, resulting in the use of controversial methods like chemical or electrical aversion therapies.

Although the financing of media campaigns is another attempted method of public education Boularte, Mossialos, and Rudisill (2011) came up with examples of its poor efficacy from analysing the data provided by the 2008 flash Eurobarometer survey "Young People and Drugs", according to which young people ended up developing only a minimal perception of the risks associated with alcohol consumption.

\section{Alcohol-related Policies in the European Union}

In trying to implement the recommendations of the 1977 WHO's Thirtieth Health Assembly, the European Economic Community has developed a regional strategy tailored to the specifics of each country (Österberg and Stenius, 1989). Under the title "Targets for Health for All" it stipulated new regulations against drug and alcohol abuse based on Target 17 objective stating: "By 1995, in all Member States, there should be significant decreases in health-damaging behaviour, such as overuse of alcohol and pharmaceutical products; use of illicit drugs and dangerous chemical substances; and dangerous driving and violent social behaviour. The 
attainment of this target could be significantly supported by developing integrated programmes aimed at reducing the consumption of alcohol and other harmful substances by at least $25 \%$ by the year 2000" (World Health Organization, 1985, p. 69).

The new recommendations were supposed to include changes in advertising policies and alcohol taxation in a manner that will garner broad public support, as well as new and innovative methods of tackling alcoholism (World Health Organization, 1985, p.73).

Although at present most responsibility for tackling alcohol-related problems lie on the shoulders of national institutions, the European Union is developing multilevel governance systems that involve a wide array of national and international institutions (Princen, 2007). In the European Union, there are three levels of governance involved in tobacco management: the local level, the national level and the European level. Assare, Cairney and Studlar (2009) in comparing the system of regulatory federalism to that of multi-level governance in EU and Britain, concluded that, although not ideal, the multi-level approach is preferable.

In Europe, the blood alcohol content (BAC) limit for driving vehicles has always been established by national governments. In 1998, the European Commission issued a draft proposal to harmonise the BAC at $0.5 \mathrm{mg} / \mathrm{l}$ among all member states. Although the proposal was rejected as exceeding the jurisdiction of EU many member states have reduced the limit (Albalate, 2008, p. 4). Although lacking inter-national convergence in alcohol policy-making, the principle of mutual recognition functions as a response to dealing with measures of differing policy imperatives, or lack of regulatory equivalence (McNaughton and Lo, 2017).

The reported legal age limits specified per European country for on-premise sales (bar or restaurant), off-premise sales, consumption and possession in public and private areas, show that all member states regulated it to be between 16 and 18 years old, but with different application, according to whether it pertains to soft (low alcohol) or hard liquor. Sixteen years old is a common age limit for purchasing Low Alcoholic beverages on-premise in most countries around the continental centre of Europe (Mulder and De Greef, 2013, p. 22). There are nevertheless differences in the regulation of the age limits for the consumption and possession of alcohol in the public space as opposed to the private one. Germany, Portugal and Romania regulate consumption, but not possession in public. Only 6 out of EU 28 set an age-limit for consumption and even possession in private (Estonia, Finlanda, Lithuania, Slovakia, Sweden and Britain).

The strictness of alcohol control policies across the European Union has been the subject of several research studies. The "Bridging the Gap" project initiated by Eurocare and partially financed by the EU had, as one of its three task forces, an Alcohol Policy Task Force mandated to compile country reports on alcohol policies and to create a measurement scale for alcohol policy strictness (Karlsson and Österberg, 2007). The results from applying the measurement instrument in 2006 showed remarkable differences between member states. On a scale from 0 to 40, (0 signifying no control at all and 40 strictest controls), the countries ranked surprisingly wide apart, ranging from those of minimal control like Luxembourg, Cyprus and Czech Republic at 4.4, and Greece at 4.5 to quite strict ones like 
Norway at 37.5. Although the instrument seemed straight forward, users have been cautioned to use it with caution.

Europeans' attitude towards alcohol-related policies has been polled by a RARHA SEAS survey administered in 20 European jurisdictions from 19 countries, ranging from the Iberian peninsula in the far west, to Scandinavia, and from Greece and Italy, to the Baltic countries, Poland and the UK. It revealed a certain amount of consensus that the best policy mix seemed to be a combination of public information and education, together with random breathalyser tests for drivers. Respondents also believed that public authorities had the responsibility to protect people from being harmed by their own drinking. A lesser consensus emerged about various other alcohol policy measures; opinions on various restrictions on alcohol availability and affordability were split almost $50 / 50$ between supporters and opponents of it (Moskalewicz, Room, and Thom eds., 2016).

The report also revealed that the differences in opinions on alcohol policy were to a large measure culturally determined. The opinion that public authorities have the responsibility to protect people from themselves when drinking in excess was assumed by $80 \%$ of southerners (French, Spaniards, Portuguese and Greeks) and only $40 \%$ or northerners like the Danes or the Austrians.

\section{The Effectiveness of European Policies in regard to Alcohol}

Looking at evidence-based practice in addiction studies, Miller, Babor, McGovern, Obot, and Bühringer (2017) analysed some of the ethical issues arising from the involvement of different actors like researchers, journalists, suppliers, financiers, authorities and others in the process. Their conclusions were that the influence is quite strong and that it sometimes threatens the credibility of studies and of their results. Among the forms of unwarranted influence, they mention direct censorship, limitation of access to data, uncertainty of financing, the placement of less qualified, more pliable scientists and agenda setting or agenda dilution according to special political, financial or ideological interests. The preservation of academic freedom, of scientific integrity and of public trust requires diverse strategies to be employed by those responsible for the production and dissemination of research results, strategies like the revelation of financing sources, the issuance of statements by scientists and reviewers to attest they had full control of the process at all times and pre-registration with clinical-trial registers (Miller, Babor, McGovern, Obot and Bühringer, 2017: 338-339).

The public recommendation ALCOLAW (Van Havere et al., 2017) analysed the effects of the change from 16 to 18 of the minimum legal drinking age between 2002 and 2014 on the Flemish and the Belgians. The report states a significant drop in alcohol consumption during the period among adolescents, with the caveat that other factors would have likely been involved also. A similar look at the global level showed similar results, fact that also suggests other factors might have been at play. 
This finding suggests that a first recommendation may be to not prioritise the increase of the minimum legal drinking age (Van Havere et al., 2017: 5). Another 24 recommendations confirm that the approach to the problem should be multi-factorial and multi-level and should preferably be based on three pillars: prevention, regulation and enforcement.

One way to gauge the efficacy of alcohol policies is to simply ask the potential consumers. Special subject-targeted Eurobarometers capture various opinions on issues like the frequency or the quantity of alcohol consumption. The last Eurobarometer $(72.3,2010)$ reveals that the level of alcohol consumption rose from 2003 to 2006 after which it flattened between 2006 and 2009. The general feeling is that while the lack of a notable increase is good news overall, the lack of a notable decrease is not so good news, casting a shadow on the efficacy of the policies so far.

\section{Conclusion}

Like in all social intervention, there are many factors which cannot be controlled, and that can generate more or less desired effects. In the case of public policy on alcohol consumption, aside from the specific and intended public measures, there also are at play less desired interferences that affect the results of analyses. In a world of abundance, the consumption of alcohol (like that of other controversial items like fats, sugars, etc.) remains a problem of public policy, due to its biological, psychological and social effects. This is why not abstinence appears to be the key, but rather a responsible level of consumption.

A proper evaluation of the efficacy of public policies in this field requires a complex research of a complex phenomenon. It also demands the availability of standardised instruments and of systems of indicators, which allows the collection of long-term data. The available data so far shows a wide array of policy attempts, but also a wide array of outcomes, not always very conclusive. The challenges in alcohol policy monitoring are related to the difficulties of obtaining sufficiently relevant data. Being riddled by the problems of scarcity of long-term data, of gaps in the continuity of statistical series, of the limited availability of only sparse, punctual or occasional data, of doubts in regard to the reliability or credibility of findings, of substantial amounts of facts that elude recording, the analyses can be vague and approximate at best.

The efficacy of European strategies for reducing the harmful levels of alcohol consumption so far appears limited. One of the reasons could be the abovementioned lack of quality, timely and relevant data. However, would more data save the problem? Or should the question be asked differently to begin with? It is the opinion of the author that an important question to ask is to what extent, improvements in the social status and in the quality of life of heavy drinkers would result in a reduced and more responsible alcohol consumption? 


\section{References}

Adrian, M. (1984). International Trends in Alcohol Production, Trade and Consumption, and Their Relationship to Alcohol-Related Problems, 1970 to 1977. Journal of Public Health Policy,5(3), 344-367.

Albalate, D. (2008). Lowering Blood Alcohol Content Levels to Save Lives: The European Experience. Journal of Policy Analysis and Management, 27(1), 20-39.

Anderson, P., Braddick, F., Reynolds, J,. and Gual, A. (eds). (2012). Alcohol Policy in Europe: Evidence from AMPHORA. In: The AMPHORA project, available online: http://www.amphoraproject.net/

Asgeirsdottir, T. \& McGeary, K. (2009). Alcohol and Labor Supply: The Case of Iceland. The European Journaland of Health Economics, 10(4), 455-465.

Assare, B., Cairney, P, and Studlar, D.T. (2009). Federalism and Multilevel Governance in Tobacco Policy: The European Union, the United Kingdom, and Devolved UK Institutions. Journal of Public Policy, 29(1), 79-102.

Babor, T., Morisano, D., Noel, J., Robaina, K., Ward, J., and Mitchell, A. (2017). Infrastructure and Career Opportunities in Addiction Science: The Emergence of an Interdisciplinary Field. In: Babor T., Stenius K., Pates R., Miovský M., O’Reilly J., and Candon P. (Eds.), Publishing Addiction Science: A Guide for the Perplexed, London: Ubiquity Press (pp. 9-34).

Bjarnason, T., Thorlindsson, T., Sigfusdottir, I., and Welch, M. (2005). Familial and Religious Influences on Adolescent Alcohol Use: A Multi-Level Study of Students and School Communities. Social Forces, 84(1), 375-390.

Borisch, B. (2014). The Federation's Pages. Journal of Public Health Policy, 35(2), 249257.

Boularte, A. T., Mossialos, E., and Rudisill, C. (2011). The Impact of Alcohol Policies across Europe on Young Adult's Perceptions of Alcohol Risks. CESifo Economic Studies, 57(4), 263-788.

Brady, M. (2017). Learning to Drink: The Social History of an Idea. Teaching 'Proper' Drinking” in Clubs and Pubs in Indigenous Australia (pp. 1-34). Canberra: ANU Press. Retrieved from http://www.jstor.org/stable/j.ctt20krxz1.9

Carpenter, C. and Dobkin, C. (2011). The Minimum Legal Drinking Age and Public Health. The Journal of Economic Perspectives, 25(2), 133-156.

Casswell, S. and Maxwell, A. (2005). Regulation of Alcohol Marketing: A Global View. Journal of Public Health Policy, 26(3), 343-358.

Chang, P., Wu, L., Chen, Y., Chuang, C., Hsieh, W., Lin, S., and Chen, P. (2010). Women's Perceptions of Their Husband's Drinking Behavior as a Risk Factor of Their Health-Related Quality of Life in the Postpartum Period. Quality of Life Research, 19(1), 47-53.

Cook, P., Ostermann, J., and Sloan, F. (2005). The Net Effect of an Alcohol Tax Increase on Death Rates in Middle Age. The American Economic Review, 95(2), 278-281.

EC (2010). Eurobarometer 72.3, 2010, EU Citizens' Attitudes Towards Alcohol. Directorate General Communication. Brussels. Retrieved from https://ec.europa.eu/health/sites/ health/files/alcohol/docs/ebs_331_en.pdf.

Forster, T.A., Kentikelenis, T., and Bambra, C. (2018). Health Inequalities in Europe: Setting the Stagefor Progressive Policy Action. Brussels: Foundation for European Progressive Studies (FEPS) \&Think-tank for Action on Social Change (TASC). 
Freudenberg, N. (2012). The Manufacture of Lifestyle: The Role of Corporations in Unhealthy Living. Journal of Public Health Policy, 33(2), 244-256.

Glatz, T., Stattin, H., and Kerr, M. (2012). A Test of Cognitive Dissonance Theory to Explain Parents' Reactions to Youths'Alcohol Intoxication. Family Relations, 61(4), 629-641.

Golden, J. (1999). An Argument That Goes Back to the Womb: The Demedicalization of Fetal Alcohol Syndrome, 1973-1992. Journal of Social History, 33(2), 269-298.

Goldfarb, A. and Tucker, C. (2011). Advertising Bans and the Substitutability of Online and Offline Advertising. Journal of Marketing Research, 48(2), 207-227.

Grant, M. (1985). Alcohol Policies. WHO Regional publication, European series No. 18.

Hellowell, M., Smith, K., and Wright, A. (2016). Hard to Avoid but Difficult to Sustain: Scotland's Innovative Health Tax on Large Retailers Selling Tobacco and Alcoho. The Milbank Quarterly, 94(4), 800-831.

Hemenway, D. (2001). The Public Health Approach to Motor Vehicles, Tobacco, and Alcohol, with Applications to Firearms Policy. Journal of Public Health Policy, 22(4), 381-402. doi:10.2307/3343157.

Jarl, J., Gerdtham, U., Lyttkens, C., Lithman, T., and Merlo, J. (2006). The Danish Effect on Swedish Alcohol Costs: An Analysis Based on Hospitalization Data from Southern Swede. The European Journal of Health Economics, 7(1), 46-54.

Jernigan, D. (1999). The Global Expansion of Alcohol Marketing: Illustrative Case Studies and Recommendations for Action. Journal of Public Health Policy, 20(1), 56-80. doi: $10.2307 / 3343259$.

Jernigan, D. and Rushman, A. (2014). Measuring Youth Exposure to Alcohol Marketing on Social Networking Sites: Challenges and Prospects. Journal of Public Health Policy, 35(1), 91-104.

Karlsson, T., and Österberg, E. (2007). Scaling Alcohol Control Policies Across Europe. Drugs: education, prevention and policy, 14(6), 499-511.

Katikireddi, S., Bond, L., and Hilton, S. (2014). Changing Policy Framing as a Deliberate Strategy for Public Health Advocacy: A Qualitative Policy Case Study of Minimum Unit Pricing of Alcohol. The Milbank Quarterly, 92(2), 250-283.

Keenan, K., Kenward, M., Grundy, E., and Leon, D. (2014). The Impact of Alcohol Consumption on Patterns of Union Formation in Russia 1998-2010: An Assessment Using Longitudinal Data. Population Studies, 68(3), 283-303.

Kessler, D. (2005). Alcohol Marketing and Youth: The Challenge for Public Health. Journal of Public Health Policy, 26(3), 292-295.

Lierse, H. (2012). European Taxation During the Crisis: Does Politics Matter? Journal of Public Policy, 32(3), 207-230.

MacDonald, Z. and Shields, M. (2001). The Impact of Alcohol Consumption on Occupational Attainment in England. Economica, 68(271), 427-453.

Mäkelä, K. and Viikari, M. (1977). Notes on Alcohol and the State. Acta Sociologica, 20(2), 155-179.

McDaid, D., Quaglio, G., De Campos, A., Dario, C., Van Woensel, L., Karapiperis, T., and Reeves, A. (2013). Health Protection in Times of Economic Crisis: Challenges and Opportunities for Europe. Journal of Public Health Policy, 34(4), 489-501.

McNaughton, A. and Lo, J. (2017). 'Mutual Evaluation': A New Policy Tool for Dealing with 'Behind the Borders’ Barriers. In: Elijah A., Kenyon D., Hussey K., and Van der 
Eng P. (Eds.), Australia, the European Union and the New Trade Agenda Australia: ANU Press: 163-182. Retrieved from http://www.jstor.org/stable/j.ctt1sq5ttx.14

Miller, P., Babor, T., McGovern, T., Obot, I., and Bühringer, G. (2017). Relationships with the Alcoholic-Beverage Industry, Pharmaceutical Companies, and Other Funding Agencies: Holy Grail or Poisoned Chalice?" in Babor T., Stenius K., Pates R., Miovský M., O'Reilly J., and Candon P. (Eds.), Publishing Addiction Science: A Guide for the Perplexed, London: Ubiquity Press: 323-352. Retrieved from http:// www.jstor.org/stable/j.ctv3t5qxw.22

Mosher, J. and Yanagisako, K. (1991). Public Health, Not Social Warfare: A Public Health Approach to Illegal Drug Policy. Journal of Public Health Policy, 12(3), 278-323. doi: $10.2307 / 3342844$.

Moskalewicz, J., Room, R., and Thom, B. (eds). (2016). Comparative Monitoring of Alcohol Epidemiology Across the EU. Baseline Assessment and Suggestions for Future Action. Synthesis Report.

Mulder, J. and de Greef, J. (2013). Eyes on Ages. A Research on Alcohol Age Limit Policies In European Member States. Legislation, Enforcement and Research. Utrecht: European Commission. Retrieved from https://www.drugsandalcohol.ie/20755/

Ogenchuk, M. (2012). High School Students' Perceptions of Alcohol Prevention Programs. Canadian Journal of Education / Revue Canadienne De L'éducation, 35(1), 156170.

Österberg, E. and Stenius, K. (1989). Health for All by the Year 2000: Alcohol and the Nordic Countries. Journal of Public Health Policy, 10(4), 499-517.

Parker, R. and Cartmill, R. (1998). Alcohol and Homicide in the United States 1934-1995: Or One Reason Why U.S. Rates of Violence May Be Going Down. The Journal of Criminal Law and Criminology (1973-), 88(4), 1369-1398.

Princen. S. (2007). Advocacy Coalitions and the Internationalization of Public Health Policies. Journal of Public Policy, 27(1), 13-33.

Rehn, N., Room, R., and Edwards, G. (2001). Alcohol in the European Region Consumption, Harm and Policies, World Health Organization Regional Office for Europe.

Ross, C., Ostroff, J., and Jernigan, D. (2014). Evidence Of Underage Targeting Of Alcohol Advertising On Television In The United States: Lessons from the Lockyer v. Reynolds Decisions. Journal of Public Health Policy, 35(1), 105-118.

Skog, O. (2006). Studying Cultural Change: Were the Changes in Alcohol and Coffee Consumption in the Ni neteenth Century a Case of Beverage Substitution?. Acta Sociologica, 49(3), 287-302.

Spach, M. and Pietri, A. (2018). Le binge drinking est-il toujours profitable à l'industrie alcoolière?: Un modèle épidémique de la consommation d'alcool. Revue économique, 69(4), 635-646.

Ştefani, C. (2018). Crime and Alcohol and Drug Control. Approaches and Trends at International Level. Revista de asistență socială, anul XVII, nr. 4/2018, 137-146.

Thorlindsson, T., Bjarnason, T., and Sigfusdottir, I. (2007). Individual and Community Processes of Social Closure: A Study of Adolescent Academic Achievement and Alcohol Use. Acta Sociologica, 50(2), 161-178.

Van Havere, T., Dirkx, N., Vander Laenen, F., De Clercq, B., Buijs, T., Mathys, C., van Praet S., Deforche B., El Houti, A., Van Damme, J., Van der Kreeft, P., and Lemaïtre A. (2017). The Law Of 2009 Concerning The Selling And Serving of Alcohol to Youths: 
From State of The Art to Assessment. Policy recommendations Overview. Brussels : Belgian Science Policy 2017. (BRAIN-be - (Belgian Research Action through Interdisciplinary Networks. Retrieved from https:/www.belspo.be/belspo/fedra/ DR/DR71_ALCOLAW\%20policy\%20recommendations\%20overview_en.pdf

World Health Organization (2014). Global Status Report On Alcohol And Health, Geneva, Switzerland, Retrieved from https://www.who.int/substance_abuse/publications/ global_alcohol_report/msb_gsr_2014_1.pdf?ua=1

World Health Organization (2018). Global Status Report On Alcohol And Health 2018, Retrieved from https://www.who.int/substance_abuse/publications/global_alcohol_ report/en/

World Health Organization (WHO). (1985). Targets For Health For All 2000. Targets In Support Of European Regional Strategy For Health For All, Copenhagen, Denmark. 